\title{
Prototyping a Conversational Agent for AI-Supported Ideation in Organizational Creativity Processes
}

\author{
Nicole Debowski \\ University of Hamburg \\ n-debowski@t-online.de
}

\author{
Navid Tavanapour \\ University of Hamburg \\ navid.tavanapour@uni-hamburg.de
}

\author{
Eva A. C. Bittner \\ University of Hamburg \\ eva.bittner@uni-hamburg.de
}

\begin{abstract}
In this study, we present design guidelines (DGs) for the development and improvement of a virtual collaborator (VC) for Design Thinking (DT). Based on interviews in an ex-ante study, we designed a first prototype of a VC. From an ex-post evaluation using focus group discussions, we derive strengths, weaknesses, opportunities and threats of the VC. Strengths of the VC are good structure, giving inspiration as well as pace and accuracy. Opportunities are to set level of detail, give a more humane representation, and linking search with other DT phases. Weaknesses are not always suitable content and the VC being rather suitable for research phases as well as one-sided communication and no empathy. Threats are questionable search filters and too narrow focus of search. We then derived DGs for further improvement of the VC, addressing the weaknesses, threats and ideas from participants.
\end{abstract}

\section{Introduction}

Due to the Covid 19 pandemic and the recurring lockdown situations since March 2020, the world of work has been forced to move from a presence-oriented and analog environment to a virtual one in a very short time. Employees have therefore been confronted with virtual tools with the help of which they collaborate to fulfill their professional activities [1]. One scenario for such collaboration are digital workshops within organizations that were conducted on-site before the pandemic. In addition to benefits, virtual collaboration also brings new challenges for workshop facilitators and participants. In the virtual setting, for example, there is a lack of nonverbal communication and interaction, which can lead to a different team atmosphere [2-3]. Furthermore, facilitators and participants are confronted with several different streams of communication and information simultaneously via speech and text [4-5]. Even supposedly small interactions such as pointing, highlighting, or organizing always require a tool function and virtual effort, which is less complicated in on-site workshops. These can lead to increased stress, so called technostress that Christian et al. define as "an adaptation problem because of the inability of workers to deal with new ICTs that are changing rapidly and healthily using them" [4] and require automated support for virtual workshops [4-6]. Especially during creative work, the lack of appropriate tools for digital visualization is problematic [6].

To support virtual creative collaboration, a virtual collaborator (VC) can be designed. The VC is a conversational agent (CA) based on artificial intelligence (AI) which is able to perceive its environment, process information, make and learn decisions, act on them, and interact with humans and other machines to achieve a common task goal with more or less autonomy [7]. Due to their constant and rapid development, as well as their adaptability to people's needs, collaboration with CAs is becoming more and more attractive [8]. However, a VC goes further in this respect: it is not limited to assistance functions, but should be considered as an equal virtual teammate in a collaborative work environment, acting with the user [9]. We are looking at an alternative to conventional ideation sessions for creative units in the automotive industry by providing a creative impulse generator that supports virtual ideation sessions. Our focus is an organizational environment that worked mostly co-located beforehand and is particularly new to virtual collaboration. The focus groups we interview are familiar with the DT approach as this is the prevalent work mode in their business units. In the following study, we want to find answers on the following research questions:

RQ1: Which strengths and weaknesses do potential users see in the presented prototype?

RQ2: Which opportunities and threats do potential users see in the presented prototype?

RQ3: What wishes and ideas do potential users have in order to improve the prototype's usability?

The research questions aim to obtain feedback on the artifact - the prototyped VC - with respect to 
strengths, opportunities, weaknesses, and threats of the VC. Further design ideas will also help in the further development. With the help of the feedback, the artifact is to be improved. In this paper, we firstly present theoretical background about cooperative creativity and the implementation of conversational agents in this regard. Afterwards, we derive strengths, weaknesses, opportunities and threats (SWOT) as well as ideas on the design of a VC. Based on two iterations of developing a VC using expert interviews (ex-ante) as well as focus group discussions on a prototyped VC (expost), we derive three additional DGs for further development and improvement of the VC.

\section{Theoretical Background \& Related Work}

\subsection{Cooperative Creativity and Design Thinking}

Sonnenburg [10] defines creativity as follows: "Creativity is the context-bound potential for meaningful novelty that unfolds in action" [10] whereas he defines cooperative creativity simply as creativity that is performed by two or more people. Cooperative creativity is influenced by four important parameters. The first parameter is cooperation itself. Argyle [11] defines cooperation as "acting together, in a coordinated way at work, leisure or in social relationship, in the pursuit of shared goals, the enjoyment of the joint activity, or simply furthering the relationship." [11]. Besides cooperation, communication is an essential parameter of creativity and a core element of creative cooperation. Two important and fundamental theories exist in this regard. According to Luhmann [12], communication consists of three selections: the selection of an information, that of a communication or that of an understanding. He distinguishes between the action and the communication itself. He defines that action is the mere communication of a piece of information, while communication is the understanding of the information, or the understanding that a piece of information has been communicated [12].

The third important parameter is the human being as a central actor, who can grasp his environment multisensually, but also via different communication media. Humans possess this ability due to their biogenetic systems as well as due to their nervous and psychic systems and organism. Luhmann explains this as the thoughts or feelings are not relevant for the maintenance of the communicative process, but only the communicated information. Language has a significant influence on creativity because of its diversity. It can activate creativity [10].
The last important parameter is interaction. It is the "reciprocal influence of individuals on each other's actions during their immediate physical presence" [13]. The prerequisite for this is the joint presence of people, as well as the perception between people. A situationbound perceptual space is created. Important processes are then perceiving as well as communicating. The perception is thereby a precondition in the environment, while the communication is already the operative elaboration of the interaction. Presence enables reciprocal perceptions and orientations, and opens and closes interaction. For an interaction to persist, at least two communication participants are needed to support the communication process. In addition, direct exchange of information allows for rapid response and feedback. This leads to a creativity dynamic, which is particularly important for the development of something new.

Finally, communication in interaction insists on the "turn-taking principle," which states that only one person speaks while everyone else listens. Typically, the roles of speaker and listener alternate permanently. This approach to the topic ultimately achieves actual engagement with it, whereby speech contributions are selected and controlled, and complexity is reduced in this way [10].

Design Thinking (DT) is one method for cooperative creativity. DT is a method for solving existing problems, and involves various stakeholders with different backgrounds at an early stage [14]. The process discussed here is the approach in the 6-phase model according to Meinel et al. [6] (see Figure 1). DT follows a structured, iterative process in which a multidisciplinary team uses various (creativity) methods to achieve the phase goal [15].

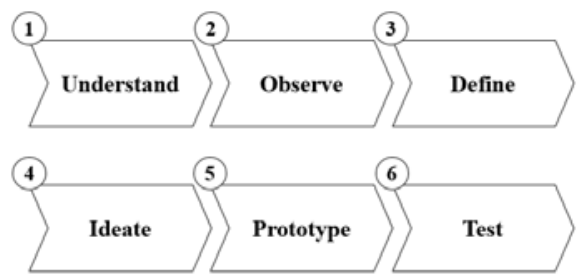

\section{Figure 1: 6 step Design Thinking process according to [6]}

In this approach, the phases are Understand, Observe, Define, Ideate, Prototype and Test, which build on each other but can be iterated if needed [16]. The Ideate phase is the focus of this study. Schallmo \& Lang describe it as follows: "In this phase, ideas are generated through the use of creativity techniques which are intended to fulfill the previously identified needs. These ideas are grouped and revised. Subsequently the ideas are described and evaluated." [15]. People and their needs represent the central source of inspiration for new ideas. Only in second and third place it is examined 
which ideas are technically feasible, and economically viable [17].

Usually, ideas are developed with the help of brainstorming or brainwriting [18], individual work is combined with group work and brainstorming is combined with brainwriting [19]. Following Engeln [20], an introduction is first given by the facilitator [20]. Then, in a first round, ideas are obtained and presented in writing or visually. These are hung up in a gallery, for example on metaplan walls, and discussed to develop them further afterwards. Finally, the ideas are presented to the team and grouped into a pool of ideas [20].

But how can cooperative creativity be promoted in ideation sessions, which are executed exclusively in a virtual environment and not in presence? In the next chapter, we will show how this process can benefit from the application of an appropriate design of a VC.

\subsection{Artificial Intelligence \& Conversational Agents}

Increasingly in focus and closely linked to the field of AI are human-like conversational agents (CA) such as Steve Worswick's project "Mitsuku" [21]. The use of CAs is particularly suitable for frequent requests for simple information, but also in sales for gaining new customers and customer retention. They can also be utilized for services within companies and for HR processes [22]. Technically, today's CAs are usually based on AI. Siepermann et al. state that "[AI] deals with methods that enable a computer to solve tasks that [...] would require human intelligence." [23].

The technology allows to collect, analyze, synthesize, and identify patterns that can be used directly in ideation sessions [24-25] as well as have a direct impact on both the outcomes of a workshop and the behavior of participants [26]. Tseng et al. (2019) show that a CA can also help in team formation by analyzing member candidates in a psychological manner to identify matching profiles [27]. While the first three phases of the DT process - such as delivering information and suggestions [3], as well as analyzing data [25] can be implemented well through AI, applications that address ideation and other creative processes are lacking [28]. A large number of research articles already address the collaboration between humans and technologies such as AI, showing a great potential of AI for the future of work [29-32]. Specific factors such as trust and skepticism towards AI [33-34] are already being explored.

In particular, the use of machine learning, whereby a computer independently generates knowledge from experience, is suitable in the implementation of CAs, especially natural language processing and understanding. The CA processes unstructured strings of letters, such as transposed words, and derives the correct content from them [35]. Natural language generation, i.e. the automatic production of natural language, is used in the context of CAs to formulate an answer for the dialog that the user can understand. Existing information such as formulations and text modules are supplemented with dynamic information to form complete sentences. This also makes it possible to analyze emotions and moods based on the written text, such as through IBM's Watson Tone Analyzer [36] or Text Analytics from Microsoft [37].

However, we follow the definition of the virtual collaborator (VC) by Siemon et al. who define it as a "coequal virtual teammate in a collaboration setting" [9]. This term will be used in the following sections. In the following, we want to present our understanding of DT and ideation sessions that need to be supported by a VC for virtual ideation sessions.

\section{Research Approach}

\subsection{Design Science Research}

We conducted a Design Science Research (DSR) project along the three-cycle view of Hevner [38] (Figure 2) to design and develop an artefact, which in our case is the VC [38]. To do so, we start the relevance cycle to inform the design of the artefact with insights from the application domain, which in our case are insights from experts within an organization. Additionally, we also start the rigor cycle to consider insights from the knowledge base regarding conversational agents and creativity for the VC. In sum we derive design guidelines within the design cycle and utilize them to build the artefact (see section 4). We evaluate our artefact before we report the results to the application domain and the knowledge base to close the relevance and rigor cycles.

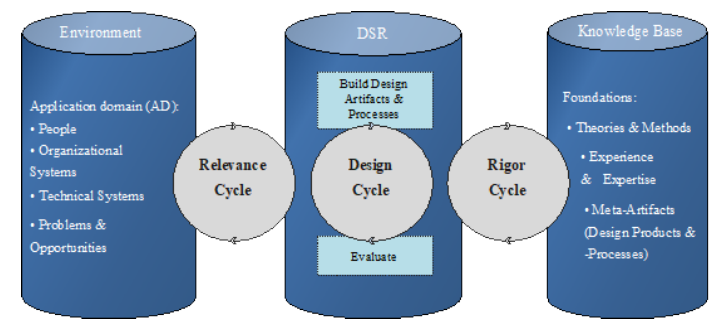

Figure 2: Three-Cycle View according to [38]

Venable et al. [39, 41] propose a 2-by-2 framework of evaluation strategies in DSR. On the one hand, the framework shows the dimension artificial vs. natural evaluation against ex-ante vs. ex-post evaluation on the other hand [39]. Distinguished by the time when the evaluation is conducted, ex-ante evaluation allows to 
evaluate a system or a technology before it is chosen and implemented whereas ex-post evaluation is conducted after implementation [40]. This allows not only a variety of combinations in the evaluation, but also the multiple employment of methods, depending on the artifact and the goal [41]. In the present case, the goal is to achieve rigor, i.e., that the artifact produces improvement despite organizational difficulties.

\subsection{Expert Interviews (Ex-Ante)}

We derived DGs for the VC from literature, conducted expert interviews, and validated them in an ex-ante qualitative study according to Gregor et al. [42]. We collected data from the perspective of potential users of a VC by conducting twelve semi-structured interviews lasting thirty to forty minutes [43], addressing challenges of digital workshops as well as requirements for a VC related to them. The participants were selected according to their role as facilitator (F) or participants (P) as well as according to their respective workshop experience (for F: High > 50; Average < 50 workshops; for P: High $>10$ workshops; Average $<10$ workshops). The DGs (see section 4) were developed among others following the approach of Gregor et al. [42] which states to develop DGs according to the following structure: "For (implementers) to (aim) for (users) in (which context) (actions, use of other artifacts, series of these actions) lead to or allow users to accomplish aim (justification for believing that mechanisms will lead to achieving the aim)".

\subsection{Focus groups (Ex-Post)}

For ex-post evaluation, a prototype was built based on the DGs from the qualitative study as well as on theoretical input stated in section 2 and 3. According to March \& Storey [44], a prototype is a suitable method to generically implement a solution for a certain problem to assess the solution's suitability [44]. The specific goal is to evaluate the current prototype and to further develop the prototype with additional functionalities and design features, thus, deriving further DGs [41].

In the ideation phase, ideas will be created by using different creativity techniques, which might be able to fulfill the previously identified needs. These ideas are grouped and revised. Subsequently the ideas are described and evaluated [15]. In the prototype, a CA was used as a source of inspiration for the ideation phase. Participants were presented with the following scenario:

"We are design thinkers, and we developed the persona Tim in the "define viewpoints" phase. In the next phase - Ideation - we want to look for a solution to Tim's challenge. Our system supports us in this."
In this study, the design challenge we want to conduct an ideation on is "How can we design the design thinking community even more interactive?" The participants should put them-selves in this situation accordingly.

As a reference point, Bucher et al. [45] suggest among others "artifact against real world" [40] where the artifact is employed in a real world situation and then assessed. In the present study, an external evaluation using the focus group method was carried out with 16 participants, "who [were] not involved in the construction of the artifact to be evaluated" [40, 46].

The participants were selected according to their experience with ideation sessions which were both conducted during community meetings and in projects (see Table 1). Three focus group evaluations were run with two groups with 5 participants each and one group with 6 participants which is sufficient according to [47]. The evaluation took place in a community meeting lasting 40 minutes.

Table 1: Sample focus group participants

\begin{tabular}{|l|l|l|}
\hline Gender & Age & Current Position \\
\hline M & 29 & UX Researcher \\
\hline M & 26 & UX Researcher \\
\hline M & 39 & Innovation Manager \\
\hline M & 38 & Innovation Manager \\
\hline M & 40 & Innovation Manager \\
\hline F & 31 & Communication Manager \\
\hline F & 30 & Innovation Manager \\
\hline M & 34 & CA Developer \\
\hline F & 28 & HR Manager \\
\hline M & 33 & HR Manager \\
\hline F & 54 & Software Developer \\
\hline$M$ & 48 & Software Developer \\
\hline M & 38 & Agile Coach \\
\hline F & 34 & UI Designer \\
\hline F & 28 & Agile Coach \\
\hline F & 52 & UI Designer \\
\hline
\end{tabular}

Since the topic is relatively new, the focus group method is suitable here. The questionnaire for the discussion was processed in a specific question sequence [48-50]:

What are your thoughts on artificial intelligence? What strengths do you see in the presented prototype? What weaknesses do you see in the presented prototype? Which opportunities do you see in the presented prototype?

Which threats do you see in the prototype presented? What ideas or wishes do you have beyond that?

Do you have any questions or comments that you have not been able to ask so far?

Venable [41] differentiates five purposes from which one stated in this study is "Evaluate an instantiation of a designed artifact to establish its utility 
and efficacy (or lack thereof) for achieving its stated purpose." [41]. This purpose implies that this evaluation is preliminary and the artifact will be further developed. As various studies state, feedback for further improvement of the design of the artifact is crucial and essential in design research $[38,51,52]$.

\section{Design and Development}

\subsection{Design of the VC}

In the following, the DGs from the expert interviews (ex-ante) are shown. We used the Microsoft Teams interface template as Microsoft Teams is also used in the organization for everyday communication and work. According to the interviewees $(n=3)$, the VC should be able to support the process by providing examples or inspiring images or sounds, information and background knowledge, conducting semantic analyses and keyword searches to generate not only data but also broad knowledge to support the research and creative phases in DT. DG1 is therefore stated as follows:

"For facilitators to support knowledge generation and exchange for participants in virtual ideation workshops in organizations by providing visualized information and background knowledge using automated semantic analyses, keyword searches, showing examples, inspiring images or sounds because searching for information regarding a specific topic might take up a lot of time during a workshop that might be needed for other phases in the DT process."

Also, the VC should take on the role of a participant and fact provider, and at the same time visualize the generated knowledge, as the interviewees stated in the ex-ante study $(n=4)$ : “The VC could offer broad knowledge on certain keywords in a visualized form”.

The interviewees suggested for the VC to either focus on harmonization and cooperation or focus on complementing their own ideas. In this way, new connections could also be pointed out to broaden the perspectives further and to obtain the broadest possible picture. DG2 is therefore stated as follows:

"For facilitators to support idea generation and evaluation for participants in virtual ideation workshops in organizations by providing information about similar products/services/ideas from the internet because research about existing products/services/ideas might be time consuming."

Using the analytical power of AI, for DG 2 it was frequently stated that the VC should be capable to analyze and evaluate the idea of a user regarding potential and fields of application. In addition, this should also be analyzed for already existing or similar ideas by connecting to the internet.

For DG3, the VC should also be able to contribute directly to broadening perspectives by providing either opposite or similar views on a topic $(n=4)$. DG3 is therefore stated as follows:

"For facilitators to support idea generation and provide inspiration for participants in virtual ideation workshops in organizations by providing new perspectives from different points of view, e.g. from a specific user group's perspective because user centricity is key for successful innovation resulting from the application of DT."

\subsection{Development of the VC}

The prototype was built using the platform Botsociety [53]. By employing the DGs from the ex-

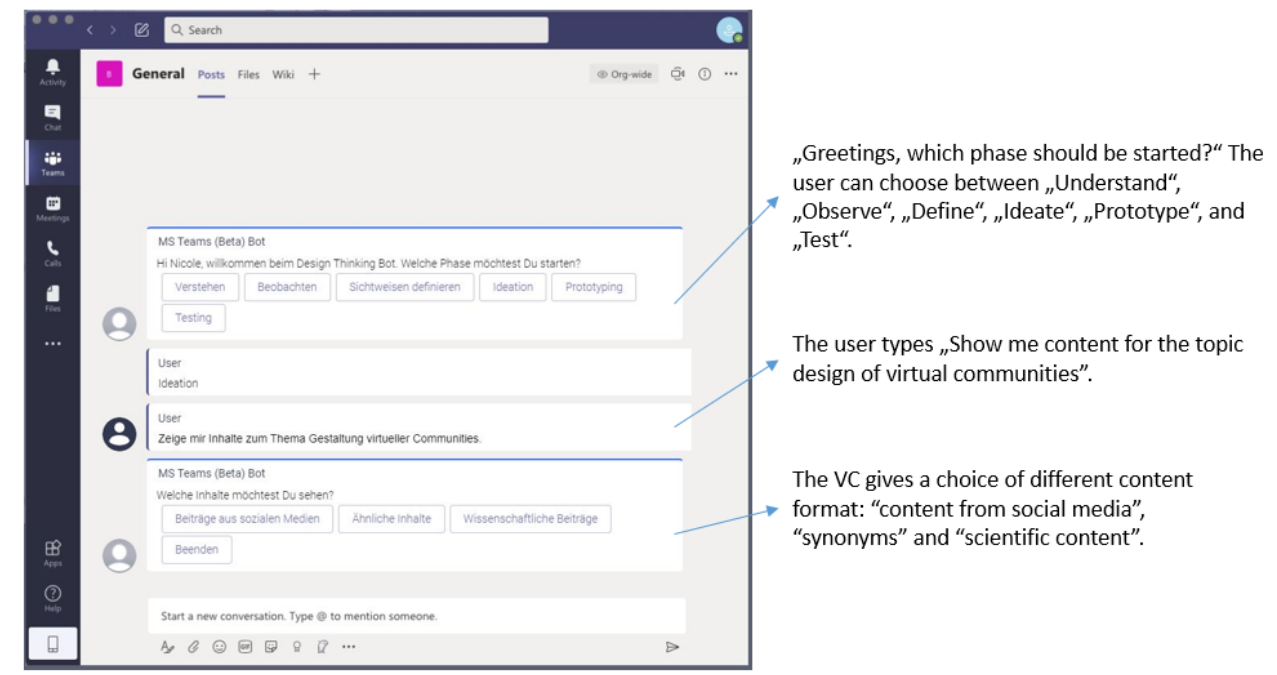

Figure 3: Snippet - Prototype: Start of the process (see https://bit.ly/3DRQOGe for more snippets) 
ante study, a conversation flow was designed according to the ideation process of [15], see section 2.3.

DG1 is applied in the VC by presenting background knowledge and information using keyword search and semantic analysis. These are delivered in the form of concrete content, such as an image, report or scientific article. This content is intended to serve as a source of inspiration and provide background knowledge on a particular topic.

This process is taken up directly in DG2, in which, with the help of the VC, information and examples of similar products or services are provided by means of a connection to the Internet as a point of comparison for what is being worked on, for example from other industries.

This step is followed by DG3, in which content is requested from different perspectives, for example from that of a previously created persona. This is indicated in the VC by having the possibility to match the generated content from the ideation session against a previously stored persona.

\section{Evaluation and Findings}

\subsection{Procedure}

The evaluation took place in a virtual meeting using Microsoft Teams. In the beginning, a basic introduction to AI and creativity was given so that all participants had the same understanding of the topic. Besides, a short discussion was conducted to further clarify and define the scope of the initial challenge to ensure that all participants have a common understanding of the conditions of the prototype. Then, the VC was demonstrated twice. Afterwards, the participants gave feedback on the prototype according to the sequence of questions above.

In the beginning of the demonstration, the VC asks which phase of the 6 step DT process the user wants to start. We click on "Ideation" to start the ideation session. After that, we type the topic of the ideation session, here "Show me content for the topic design of virtual communities". The VC gives a choice of different content format: "content from social media", "synonyms" and "scientific content". In the demonstration, we click on each format to show the respective results. On "content from social media”, we see a report about virtual communities as well as a training on building up virtual communities derived from LinkedIn. Clicking on "synonyms", we see peripheral content on this topic such as about events. On "scientific content", we get scientific papers on design guidelines for virtual communities as well as on designing a virtual learning platform from ResearchGate.
After clicking through all possibilities given in the ideation session, we get to choose from either "additional ideation", "align with previously set persona" or "finish ideation". We choose to close the ideation session, and the VC thanks us for using it as well as asking for feedback. After the first round of presenting and explaining the $\mathrm{VC}$, we ran another round.

We conducted a SWOT analysis VC and evaluated the output of the focus group discussions by phrasing and coding the contents as well as quantifying the statements. By doing so, we identified central topics as well as different opinions of the participants through inductive analysis according to Block et al. [54]. We explicitly did not consider group effects, mimics and gestures in our analysis [55].

\subsection{Focus group results}

5.2.1. SWOT Analysis. We evaluated the VC with a SWOT analysis present its result in Table 2.

Strengths: The participants of the focus groups stated that the VC is well subdivided into the sections "content from social media", "synonyms" and "scientific content" and well broken down $(n=13)$. This content selection was considered sufficient by the participants. The procedure was very easy and fast to follow, simple questions were formulated. The approach described above was considered as guiding and also as an ice breaker for initial input search: "you are guided even more based on the process of the VC". If this procedure didn't exist - the participants stated - it would be seen as an obstacle: "I know which direction I can move in". Therefore, the VC guides well because "You have to deal with what content you want". Besides, the communication with the VC was simple and good in short texts. The handling of the VC was considered as a "perfected Google search".

Table 2: Results of the SWOT analysis $(n=$ number of statements)

\begin{tabular}{|c|c|}
\hline Strengths & Weaknesses \\
\hline $\begin{array}{l}\text { - Good structure }(n=13) \\
\text { - Provides inspiration } \\
(n=8) \\
\text { - Pace \& Accuracy }(n=7)\end{array}$ & $\begin{array}{l}\text { - No suitable content }(n=7) \\
\text { - No empathy }(n=3) \\
\text { - Not suitable for ideation } \\
(n=3) \\
\text { - One-sided } \\
\text { communication }(n=3)\end{array}$ \\
\hline Opportunities & Threats \\
\hline $\begin{array}{l}\text { - } \text { Set level of detail }(n=6) \\
\text { - Link with other DT } \\
\text { phases }(n=2) \\
\text { - } \text { Text to speech }(n=2) \\
\text { - } \text { Represent more } \\
\text { humanely }(n=1) \\
\text { - } \text { Deeper evaluation } \\
(n=1)\end{array}$ & $\begin{array}{l}\text { - Provide stimuli }(n=8) \\
\text { - Questionable search filter } \\
(n=5) \\
\text { - Focus too small }(n=5)\end{array}$ \\
\hline
\end{tabular}


The VC gave a variety of sources and different foci with the sections. Although it was compared to a Google search, it was stated positively, that the VC is "made for searching innovations in the field, not only general things". The user interface was well designed using the Microsoft Teams interface template as Microsoft Teams is also used in the organization for everyday communication and work. The participants stated that the VC was easy to use: "Easy to understand, usable even without explanation, not only for design thinkers.". It was considered as an advantage that it is possible to "look at the phase first" and that "you can also text with the bot".

The content was perceived by the participants as implicit inspiration for the ideation session $(n=8)$. Especially “if I know exactly what I need, it's good”. It was also stated, that participants can learn from the function of the bot though it is important that the human user explicitly types in what he or she is looking for. Providing inspiration, a specific topic can also be perceived in a different perspective: "I realize 'wow, that could have been interpreted that way"'. According to the participants, it is especially within the ideation interesting to look at other industries and look up analogies.

The participants stated that using the VC is quick and easy $(n=7)$. Especially the pace of information being delivered by the VC was convincing to them. Getting quick information means quick progress: "You get information fast, you advance quickly". The "quick selection by just a click" was pleasant to use. The VC was also perceived as accurate, providing information and inspiration directly linked to the searched topic.

Opportunities: The participants see several opportunities to achieve better results with the VC once developed. Setting the level of detail was the most stated chance for the VC $(n=6)$, meaning providing information on related topics to broaden the focus and finding more information than the user itself would find. Also, setting specific search criteria seems important:

"One is always looking for something specific, setting the level of detail would be good". Other participants considered an advanced view: "Give the CA more criteria, refine the search, and show final results in a detailed view". After the first results, the search criteria should be refined: "If I change $\mathrm{x}$ and $\mathrm{y}$, what is the outcome?"

Besides, the participants see further opportunities for the VC by interspersing examples to a topic to stimulate thinking in a different direction: "similar content, but somehow different". Information should be presented as compressed as possible such as single words: "Short pistol shots that build on each other" rather than whole articles.
Another statement $(n=1)$ suggested a more humane representation and communication of the VC: "So far still very framed, not very human. The texts have been repetitive, if they were different words and more colloquial and nuances would differ, it would be more human”. Communicating in more informal language as well as having a less static but more natural flow of the dialog would support this suggestion.

Other statements regarding opportunities for the VC were text-to-speech and speech-to-text communication $(n=2)$, deeper evaluation using the power of AI $(n=1)$ as well as linking the contents to other DT phases, e.g. to Prototype $(n=2)$.

Weaknesses: The biggest weakness is the potentially not suitable content brought by the VC $(n=7)$. It was stated that the search is limited in the way that many suggestions are proposed to the user. Therefore, one difficulty might occur: "You cannot always select, a filter function would be very important.”. According to the participants, the content does not need to be structured to the fullest but should cluster and be more summarized: "It should be more summarized. Usually, we use Post Its, now I get articles. The results should be smaller, more compact.”

Besides, the participants stated that the VC in the current state does not deliver enough input. Alternative terms towards the topic should be searchable as well as more matching content to the topic should be shown which is a conflict to showing shorted results. Also, it was stated, that the delivered content are rather impulses like in a research phase: "The actual work, to pour the content from the article into an idea, this would have to be performed by the human.” Finally, some participants $(n=3)$ found the VC more fitting in research or in the Observe or Understand phase of DT.

A one-way communication was criticized by the participants: "The bot does not challenge me. If I don't know exactly what I need or search for, the exchange with a real person is helpful”. Also, actively ending the conversation was perceived as too exhausting: "If I don't search anymore, I don't search further. The bot should end the session by itself”. Finally, the VC did not manage to show empathy. It was perceived as not being able to recognize emotions, and that interaction and speech is lost.

Threats: The stated threats were regarding search filter and the set focus. Regarding the selection e.g. for social media $(n=5)$, the question was raised what the selection of the VC is based on: "Yes, LinkedIn shows trends, but no critical perspectives". There is a threat of one-sided information, but getting both positive and negative is considered giving a better overview of a topic. The process behind the selection should be shown: "It is not clear how he got to the result, what was the selection process?” Also, the source of the contents 
is important to accept the linked knowledge: "Where does the content come from? Fake news can be everywhere”.

Regarding the set level of detail, the participants stated that it is too small $(n=5)$. Considering this, the participants were afraid to have a very narrow view on the topic. It was assumed that the VC works with keywords: "Not really relevant content based on keywords, I think AI does not recognize the focus very much with keywords". It was considered easy to "slip into a bubble" which might lead to priming in thinking or in the ideation session itself. Besides, the participants were afraid that AI cannot recognize emotions and, therefore, does not know which emotions are most important for a community.

5.2.2. Ideas. Several ideas were developed by the participants during the discussions. The most discussed and stated idea was that the VC can provide more stimuli $(n=8)$. Using the currently provided content, the participants stated that the VC could also provide input for research, prototyping and testing, e.g. get inspiration for functions ("ideas come to you while you are building the prototype"), find interesting testing formats or go into cross sectoral research ("where else do we have this issue?”). However, this input needs to be given subtly: "creativity of the individual must be in the foreground, examples should be interspersed to a topic to stimulate to think in a different direction". Another way of providing stimuli is to deliver pictures for inspiration: "like a kind of stimulus picture method, would have opened up a different horizon”. This could support the flow of the ideation phase. Also, individual words can work as stimuli: "briefly skim over them and extract the essence to be able to say whether this gives us a new perspective”.

The participants also suggest to give the possibility to set search filters $(n=5)$. It was suggested to give a broad overview in the beginning of the search and narrow it down for further focus: "Instead of going further I'd like to narrow down the search, which context, which parts of the text are important etc. Setting in percent, e.g. $20 \%$, so side infos should come through”. Criteria catalogs could help doing so as well as stating conditions or clustering the search in phase-, content-, or group-related content: "I want to use it like spices in the kitchen, e.g. always search these pages, search with these terms, in this time period, in those languages".

The participants suggested to give different views and perspectives during the ideation phase to promote diversity. Providing a digital exchange with further views and perspectives might balance out the lack of exchange with humans. The following perspectives were suggested: experienced coach, different user groups, beforehand provided persona and different combinations of those.

\subsection{Resulting Guidelines for the VC}

We derive the following design guidelines (DG) for a VC in a virtual workshop from the conducted focus group discussions that will be used for further development and improvement of the VC. DGs were derived from the weaknesses, threats and ideas stated in the focus group discussions following the DSR approach of Hevner et al. [42] and Gregor et al. [51].

The VC should overcome one-sided communication as well as become more humane. Therefore, the VC should be able to show empathy, and deliver empathic and suitable contents for the topic. We state DG4 as follows:

"For facilitators to support diverse perspectives in virtual ideation workshops in organizations by providing a variety of views and perspectives on a topic based on different user groups because empathic thinking helps to react on previously defined challenges and needs of a persona."

Furthermore, the VC should be able to show suitable content. This goal should be achieved by giving the users the possibility to set their own focus and level of detail in order to achieve individual results. Therefore, we state DG5 as follows:

"For facilitators to support communication of participants and VC in virtual ideation workshops in organizations by providing the possibility to set a certain focus and change level of detail according individual topics and interests because different stages of ideation sessions need different detail in stimuli and results."

Besides, the VC should provide stimuli in the form of pictures or words from different perspectives, considering the beforehand and following DT phases as well as get further information on how other industries deal with a specific topic, we derive DG6:

"For facilitators to provide stimuli in virtual ideation workshops in organizations by providing pictures, key words, and sounds as well as information about the specific topic in other fields/industries/... because various stimuli can bring out even more creative ideas and solutions."

\section{Contribution and Limitations}

In summary, our research contributed to theories and concepts on collaboration with AI and virtual collaboration itself $[3,7,56]$. We contribute specific DGs with regard to a prototype demonstrating AIsupported ideation sessions for users in an organizational environment, derived from weaknesses, 
threats as well as ideas stated by focus groups. The DGs can serve as a foundation for further development and improvement of the prototype as well as for further research in virtual collaboration and virtual ideation sessions supported by AI.

Our focus was to provide these for an organizational environment that worked mostly colocated beforehand and is particularly new to virtual collaboration. Especially in organizations, CAs are becoming more important which requires considering aspects such as methods and current systems used in the organization as well as reducing redundancies in tool landscape [33-34] which is provided by this study. By using the Microsoft Teams template from Botsociety, we give a realistic environment of the $\mathrm{VC}$ to the focus groups. However, CAs are mostly seen as mere support systems limited to assistance functions such as the collection, analysis and synthesis of information [2425]. In our case, we investigated how a VC as a teammate is seen by the focus groups. DT facilitators and practitioners can already derive implications from this study for their remote practice by considering the presented prototype as additional virtual teammate.

Our study shows some limitations. Even though we have looked at different business units, we have only looked at one industry so far. Further research could give a cross-industry view of the issue. This includes different approaches in creative units. In addition, the study at hand has covered virtual ideation sessions only. In addition, more focus can be placed on linking the different DT phases with each other, e.g. linking the ideation phase with the earlier definition phase and the following prototyping phase. Incorporating group dynamics should also be addressed in further studies. Finally, building on our study, further development of the prototype is necessary.

\section{References}

[1] Möhring, K., Naumann, E., Reifenscheid, M., Blom, A., Wenz, A., Rettig, T., u.a. (2020). Die Mannheimer Corona-Studie: Schwerpunktbericht zur Erwerbstätigkeit in Deutschland 20.3.-15.4.2020. Mannheim: Universität Mannheim.

[2] Shirani, A. (2006). Samling and pooling of decisionrelevant information: Comparing the efficiency of faceto-face and GSS supported groups. Information Management (43), pp. 521-529.

[3] Waizenegger, L., Seeber, I., Dawson, G., \& Desouza, K. (2020). Conversational agents - exploring generative mechanisms and second-hand effects of actualized technology affordances. Proceedings of the 53rd Hawaii International Conference on System Sciences. Hawaii, USA.

[4] Christian, M., Purwanto, E., \& Wibowo, S. (2020). Technostress creators on teaching performance of private universities in Jakarta during Covid-19 pandemic.
Technology Reports of Kansai University 62 (6), pp. 2799-2809.

[5] Besser, A., Lotem, S., \& Zeigler-Hill, V. (2020). Pschological Stress and Vocal Symptoms among University Professors in Israel: Implications of the Shift to Online Synchronous Teaching during the COVID-19 pandemic. Journal of Voice.

[6] Meinel, C., \& von Thienen, J. (2016). Design Thinking. Informatik-Spektrum (39).

[7] Seeber, I., Waizenegger, L., Seidel, S., Morana, S., Benbasat, I., \& Lowry, P. (2019). Collaborating with technology-based autonomous agents. Internet Research 30 (1), pp. 1-8.

[8] Tegos, S., Demetriadis, S., \& Karakostas, A. (2015). Promoting academically productive talk with conversational agent interventions in collaborative learning settings. Computers \& Education 8, pp. 309-325.

[9] Siemon, D., \& Strohmann, T. (2021). Human-AICollaboration: Introducing the Virtual Collaborator. Collaborative Convergence and Virtual Teamwork for Organizational Transformation. IGI Global, pp. 105-119.

[10] Sonnenburg, S. (2007). Kooperative Kreativität. Wiesbaden: Deutscher Universitäts-Verlag.

[11] Argyle, M. (1991). Cooperation: Basis of Sociability. New York: Routledge.

[12] Luhmann, N. (1993). Soziale Systeme: Grundriss einer allgemeinen Theorie. Frankfurt am Main: Suhrkamp.

[13] Goffman, E. (1978). The presentation of self in everyday life (Vol. 21). London: Harmondsworth.

[14] Brown, T., \& Katz, B. (2011). Change by Design. Journal of Product Innovation Management, pp. 381-383.

[15] Schallmo, D., \& Lang, K. (2020). Design Thinking Erfolgreich Anwenden. Wiesbaden: Springer Verlag.

[16] Plattner, H., Meinel, C., \& Weinberg, U. (2009). Design Thinking. Innovation lernen, Ideenwelten öffnen. München: FinanzBuch.

[17] Liedtka, J., \& Ogilvie, T. (2011). Designing for growth. New York, USA: Columbia Business School.

[18] Stummer, C., Günther, M., \& Köck, A. (2008). Grundzüge des Innovations- und Technologiemanagements. Wien: Facultas.

[19] Gassmann, O., \& Sutter, P. (2008). Praxiswissen Innovationsmanagement: Von der Idee zum Markterfolg. München: Hanser.

[20] Engeln, W. (2006). Methoden der Produktentwicklung. München: Oldenbourg.

[21] Sodha, S. (2019). Look deeper into the Syntax API feature within Watson Natural Language Understanding. Retrieved from https://developer.ibm.com/articles/adeeper-look-at-the-syntax-api-feature-within-watson-nlu

[22] Canonico, M., \& De Russis, L. (2018). A comparison and critique of natural language understanding tools. In Cloud Computing 2018: The Ninth International Conference on Cloud Computing.

[23] Siepermann, M., \& Lackes, R. (2019). Künstliche Intelligenz (KI). Retrieved from Definition: https://wirtschaftslexikon.gabler.de/definition/kuenstlich e-intelligenz-ki-40285

[24] Gil, Y., Greaves, M., Hendler, J., Hirsh, H. (2014). "Amplify scientific discovery with artificial intelligence" in Science. 346 (6206). pp.171-172. 
[25] Ransbotham, S., Kiron, D., Gerbert, P., Reeves, M. (2017). "Reshaping Business With Artificial Intelligence” in MIT Sloan Management Review. 59 (1). pp.1-16.

[26] Seidel, S. \& Berente, N. (2020). "Informate, and Generate: Affordance Primitives of Smart Devices and the Internet of Things" in Handbook on Digital Innovation.

[27] March, S., Hevner, A., Ram, S. (2000). "Research Commentary: An Agenda for Information Technology Research in Heterogeneous and Distributed Environments” in Information Systems Research. Vol. 11. pp.i-432.

[28] Cautela, C., Mortati, M., Dell’Era, C., Gastaldi, L. (2019). "The Impact of Artificial Intelligence on Design Thinking Practice: Insights from the Ecosystem of Startups. Strategic Design Research Journal”. 12. pp.114134.

[29] Aleksander, I. (2017). "Partners of humans: a realistic assessment of the role of robots in the foreseeable future" in Journal of Information Technology. 32 (1). pp.1-9.

[30] Louvet, J.-B., Duplessis, G.D., Chaignaud, N., Vercouter, L., Kotowicz, J.-P. (2017). "Modeling a collaborative task with social commitments". Procedia Computer Science. 112. 377-386.

[31] Bittner, E. A. C., Mirbabaie, M., Morana, S. (2021). "Digital Facilitation Assistance for Collaborative, Creative Design Processes” in 54th Hawaii International Conference on System Sciences (HICSS).

[32] Wiethof, C., Tavanapour, N., \& Bittner, E. A. C. (2021). "Implementing an Intelligent Collaborative Agent as Teammate in Collaborative Writing: Toward a Synergy of Humans and AI" in 54th Hawaii International Conference on System Sciences (HICSS).

[33] Elson, J., Derrick, D., Ligon, G. (2020). “Trusting a Humanoid Robot: Exploring Personality and Trusting Effects in a Human-Robot Partnership" in Proceedings of the 53rd Hawaii International Conference on System Sciences (HICSS).

[34] Jessup, S., Gibson, A., Capiola, G., Alarcon, M. (2020) "Investigating the Effect of Trust Manipulations on Affect over Time in Human-Human versus HumanRobot Interactions” in Proceedings of the 53rd Hawaii International Conference on System Sciences (HICSS).

[35] Kohne, A., Kleinmanns, P., Rolf, C., \& Beck, M. (2020). Chatbots - Aufbau und Anwendungsmöglichkeiten von autonomen Sprachassistenten. Wiesbaden: Springer Vieweg.

[36] IBM. (2021, 06 11). IBM. Retrieved from Services - Tone Analyzer: https://www.ibm.com/watson/services/toneanalyzer/

[37] Microsoft Azure. (2021, 06 11). Retrieved from Text Analytics:https://azure.microsoft.com/dede/services/cognitive-services/text-analytics/

[38] Hevner, A. (2007). A Three Cycle View of Design Science Research. Scandinavian Journal of Information Systems 19 (2), pp. 87-92.

[39] Venable, J. (2006). A framework for design science research activities. Proceedings of the 2006 Information Resource Management Association Conference. Washington, DC, USA.
[40] Cleven, A., Gubler, P., \& Hüner, K. (2009). Design Alternatives for the Evaluation of Design Science Research Artifacts. Proceedings of the 4th International Conference on Design Science Research in Information Systems and Technology (DESRIST '09). Association for Computing Machinery, (pp. 1-8). New York, NY, USA.

[41] Venable, J., Pries-Heje, J., \& Baskerville, R. (2012). A Comprehensive Framework for Evaluation in Design Science Research. Design Science Research in Information Systems - Advances in Theory and Practice (pp. 398-410). Las Vegas, NV, USA: 7th International Conference DESRIST 2012.

[42] Gregor, S., Kruse, L., \& Seidel, S. (2020). The Anatomy of a Design Principle. Jourcal of the Association for Information Systems.

[43] Döring, N., \& Bortz, J. (2016). Forschungsmethoden und Evaluation in den Sozial- und Humanwissenschaften (5 ed.). Berlin Heidelberg: Springer Verlag.

[44] March, S., \& Storey, V. (2008). Design Science in the Information Systems Discipline: An Introduction to the Special Issue on Design Science Research. MIS Quarterly, pp. 725-730.

[45] Bucher, T., Riege, C., \& Saat, J. (2008). Evaluation in der gestaltungsorientierten Wirtschaftsinformatik Systematisierung nach Erkenntnisziel und Gestaltungsziel. In J. Becker, H. Krcmar, \& B. Niehaves, Wissenschaftstheorie und gestaltungsorientierte Wirtschaftsinformatik (pp. 69-86). Heidelberg, Germany: Physica.

[46] Bhola, H. (1990). Evaluating "Literary for Development" Projects, Programs and Campaigns. Hamburg, Germany: Unesco Institute for Education.

[47] Tremblay, M., Hevner, A., \& Berndt, D. (2010). Focus Groups for Artifact Refinement and Evaluation in Design Research. Communications of the Association for Information Systems 26 (27), pp. 1-22.

[48] Krueger, R. (1998). Developing questions for focus groups. Thousand Oaks, London, New Delhi.

[49] Lamnek, S. (1998). Gruppendiskussion. Theorie und Praxis. Weinheim: Beltz.

[50] Dürrenberger , G., \& Behringer, J. (1999). Die Fokusgruppe in Theorie und Praxis. Stuttgart: Akademie für Technikfolgenabschätzung in Baden-Württemberg.

[51] Hevner, A. R., March, S. T., Park, J., \& Ram, S. (2004, 03). Design Science in Information Systems Research. MIS Quarterly (28:1), pp. 75-105.

[52] Kuechler, R., \& Vaishnavi, V. (2008). On Theory Development in Design Science Research: Anatomy of a Research Project. European Journal of Information Systems 17 (5), p. 489.

[53] Inc., B. (2021, 06 09). Botsociety. Retrieved from https://botsociety.io/

[54] Richard A. Block, Peter A. Hancock, Dan Zakay, How cognitive load affects duration judgments: A metaanalytic review, Acta Psychologica, Volume 134, Issue 3, 2010, Pages 330-343.

[55] Schulz, M., \& Mack Ortwin Renn, B. (2012). Fokusgruppen in der empirischen Sozialwissenschaft Von der Konzeption bis zur Auswertung. Wiesbaden: Springer. 